\title{
Development of SiC-FET methanol sensor
}

Jayita Kanungo, Mike Andersson, Zhafira Darmastuti, Sukumar Basu,

Per-Olov Käll, Lars Ojamäe and Anita Lloyd Spetz

\section{Linköping University Post Print}

N.B.: When citing this work, cite the original article.

Original Publication:

Jayita Kanungo, Mike Andersson, Zhafira Darmastuti, Sukumar Basu, Per-Olov Käll, Lars Ojamäe and Anita Lloyd Spetz, Development of SiC-FET methanol sensor, 2011, Sensors and actuators. B, Chemical, (160), 1, 72-78.

http://dx.doi.org/10.1016/j.snb.2011.07.015

Copyright: Elsevier

http://www.elsevier.com/

Postprint available at: Linköping University Electronic Press

http://urn.kb.se/resolve?urn=urn:nbn:se:liu:diva-72077 


\title{
Development of SiC-FET methanol sensor
}

\author{
Jayita Kanungo ${ }^{1}$, Mike Anderson ${ }^{2}$, Zhafira Darmastutti ${ }^{2}$, Sukumar Basu ${ }^{1}$, Per-Olov Käll ${ }^{2}$, \\ Lars Ojamäe ${ }^{2}$, Anita Lloyd Spetz ${ }^{2} *$ \\ ${ }^{1}$ IC Design \& Fabrication Centre. \\ Dept.of Electronics \& Telecommunications Engineering. \\ Jadavpur University, Kolkata-700032, India \\ ${ }^{2}$ Dept. of Physics, Chemistry and Biology, \\ Linköping University, \\ SE-581 83 Linköping, Sweden
}

*Corresponding author: Tel: + 4613281710 Fax: + 4613137568 .

*E-mail address: spetz@ifm.liu.se 


\begin{abstract}
A silicon carbide based field effect transistor (SiC-FET) structure was used for methanol sensing. Due to the chemical stability and wide band gap of SiC, these sensors are suitable for applications over a wide temperature range. Two different catalytic metals, $\mathrm{Pt}$ and Ir, were tested as gate contacts for detection of methanol. The sensing properties of both Ir gate and Pt gate SiC-FET sensors were investigated in the concentration range 0.3 $-5 \%$ of methanol in air and in the temperature range $150-350^{\circ} \mathrm{C}$. It was observed that compared to the Ir gate sensor, the Pt gate sensor showed higher sensitivity, faster response and recovery to methanol vapour at comparatively lower temperature, with an optimum around $200^{\circ} \mathrm{C}$. Quantum-chemical calculations were used to investigate the $\mathrm{MeOH}$ adsorption and to rationalize the observed non-Langmuir behavior of the response functions. The methanol sensing mechanism of the SiC-FET is discussed.
\end{abstract}

Key words: SiC, FET sensor, Pt, Ir, Methanol, Gas sensor, Solid state sensors 


\section{Introduction}

Carbon dioxide is considered as the most important greenhouse gas, since the increase in carbon dioxide concentration in the atmosphere (at present about $390 \mathrm{ppm}$ ) is believed to enhance global warming problems. Conversion of carbon dioxide from large scale industry exhausts, e.g. coal fueled power plants, to useful chemicals and new fuels is one promising way to reduce the problem. Recently research, which focuses on methanol synthesis from $\mathrm{CO}_{2}$ is published [1-3]. Methanol is a common feed stock for several important chemicals and a potential alternative energy carrier to, e.g., hydrogen. It is also a very useful organic solvent with widespread applications in the manufacturing of colors, dyes, drugs, perfumes, formaldehyde etc. Methanol is toxic and fatal to human beings even in modest concentrations [4]. The wide range of applications of $\mathrm{MeOH}$, its toxicity, and the desirability to be able to fine tune its synthesis under demanding conditions strongly suggest the need of development of reliable and selective methanol sensors.

The gas-sensing properties of nanostructured $\mathrm{ZnO}$ thin films to methanol, ethanol and propyl alcohol vapour was studied by Cheng et al. [5]. Arshak and Gaiden [6] investigated the iron and zinc oxide thick film gas sensors to detect methanol, ethanol and propanol in the concentration range of $0-8000 \mathrm{ppm}$. Neri et al. [7] reported that the addition of $\mathrm{Ce}^{3+}$ to $\mathrm{Fe}_{2} \mathrm{O}_{3}$ increases the response to methanol at low temperature $\left(<350^{\circ} \mathrm{C}\right)$. Patel et al. [4] studied an indium tin oxide (ITO) thin film gas sensor for detection of methanol at room temperature. To detect gas molecules at high temperature and in an corrosive environment, the sensor should be hard, robust, chemically inert and 
stable even at elevated temperatures. $\mathrm{SiC}$ is a wide band gap $(3.2 \mathrm{eV})$ material with break down electric field of $2.2 \cdot 10^{6} \mathrm{~V} \mathrm{~cm}^{-1}$, thermal conductivity $5 \mathrm{~W} \mathrm{~cm}^{-1} \mathrm{~K}^{-1}$ and a melting point $\sim 2700^{\circ} \mathrm{C}$, that permits its use over a wide temperature range, from RT to above $600^{\circ} \mathrm{C}$. Also the extremely good chemical inertness makes it suitable for use in aggressive environments. Since the $\mathrm{SiC}$ is commercially available as wafers, so far $100 \mathrm{~mm}$ in diameter, mass production of devices enables manufacturing of small and cheap device chips. Gas sensitive field effect devices based on silicon carbide ( $\mathrm{SiC}$ ) with catalytic gate metals are being commercialized by SenSiC AB [8]. Based on the choice of gate material and operation temperature, selectivity to different gas molecules is demonstrated [9].

During gas sensing, the sensor is exposed to methanol molecules that can react with the adsorbed surface oxygen or with the moisture present in air and then decompose to hydrogen atoms on the catalytic gate electrode surface [10-12]. In a study of methanol decomposition over a Pd membrane where the reaction species and products were analyzed by two mass spectrometers, one on each side of the membrane, it was observed that the decomposed hydrogen originated from the methyl group of methanol [10]. This was clarified through the use of deuterium atoms in different positions of the methanol molecule and the following reaction sequences were suggested.

In presence of adsorbed surface oxygen:

$\mathrm{CH}_{3} \mathrm{OH}(\mathrm{g}) \rightarrow \mathrm{CH}_{2} \mathrm{OH}_{\text {ad }}+\mathrm{H}_{\text {ad }}$ (methyl),

$\mathrm{O}_{2}(\mathrm{~g}) \rightarrow 2 \mathrm{O}_{\mathrm{ad}}$

$\mathrm{CH}_{2} \mathrm{OH}_{\mathrm{ad}}+\mathrm{O}_{\mathrm{ad}} \rightarrow 3 \mathrm{H}_{\mathrm{ad}}$ (methyl) $+\mathrm{CO}_{2}(\mathrm{~g})$,

$\mathrm{O}_{\mathrm{ad}}+\mathrm{H}_{\mathrm{ad}}$ (methyl) $\rightarrow \mathrm{OH}_{\mathrm{ad}}$, 
$\mathrm{OH}_{\mathrm{ad}}+\mathrm{H}_{\mathrm{ad}}$ (methyl) $\rightarrow \mathrm{H}_{2} \mathrm{O}(\mathrm{g})$

$2 \mathrm{H}_{\text {ad }}$ (methyl) $\rightarrow \mathrm{H}_{2}$.

In presence of moisture, the following reactions are possible:

$\mathrm{CH}_{3} \mathrm{OH}+\mathrm{H}_{2} \mathrm{O} \rightarrow 6 \mathrm{H}^{+}+6 \mathrm{e}^{-}+\mathrm{CO}_{2}$

$6 \mathrm{H}^{+}+6 \mathrm{e}^{-} \rightarrow 3 \mathrm{H}_{2}$

However, another possibility is the decomposition of methanol to formaldehyde and formic acid by reacting with the chemisorbed oxygen on the oxide surface $[4,13]$.

$\mathrm{CH}_{3} \mathrm{OH}+\mathrm{O}^{-}$ad $\rightarrow \mathrm{HCOH}+\mathrm{H}_{2} \mathrm{O}+\mathrm{e}^{-}$

$\mathrm{CH}_{3} \mathrm{OH}+\mathrm{O}_{2}^{-} \rightarrow \mathrm{HCOOH}+\mathrm{H}_{2} \mathrm{O}+\mathrm{e}^{-}$

This shows that there are quite many possible adsorbed species including hydrogen atoms or ions on the catalytic metal surfaces and some of them may spill over to the exposed oxide in the porous film. A discussion about the detection mechanism of the methanol sensor is found in the Discussion and Future work section.

In this communication, highly sensitive and fast response Pt gate SiC-FET sensors are reported for methanol detection at elevated temperatures. For comparison, the same set of experiments were carried out for Ir gate SiC-FET sensors. The adsorption of methanol was in addition investigated by quantum-chemical computations. Selectivity and crosssensitivity to some gases and stability of both sensors are also reported.

\section{Experimental}


The MISiC transistor device was designed by SenSiC AB [8] and processed from $4 \mathrm{H}-$ SiC wafers by ACREO AB [14], see schematic picture in Fig. 1. The Ohmic contacts to drain, source and the backside of the $\mathrm{SiC}$ substrate consist of $50 \mathrm{~nm} \mathrm{Ni}$, subjected to rapid thermal annealing in $\mathrm{Ar}$ at $950^{\circ} \mathrm{C}$ for 10 min and thereafter $50 \mathrm{~nm} \mathrm{TaSi} \mathrm{x}_{\mathrm{x}}+400 \mathrm{~nm} \mathrm{Pt}$ was deposited on top of the Ni. The Pt layer is necessary as an oxygen diffusion barrier for high temperature operation, while the $\mathrm{TaSi}_{\mathrm{x}}$ serves as adhesion layer between $\mathrm{Ni}$ and Pt. The different catalytic gate materials (Ir, Pt) of about $20 \mathrm{~nm}$ thickness were deposited by sputtering at high pressure which creates porous films [9].
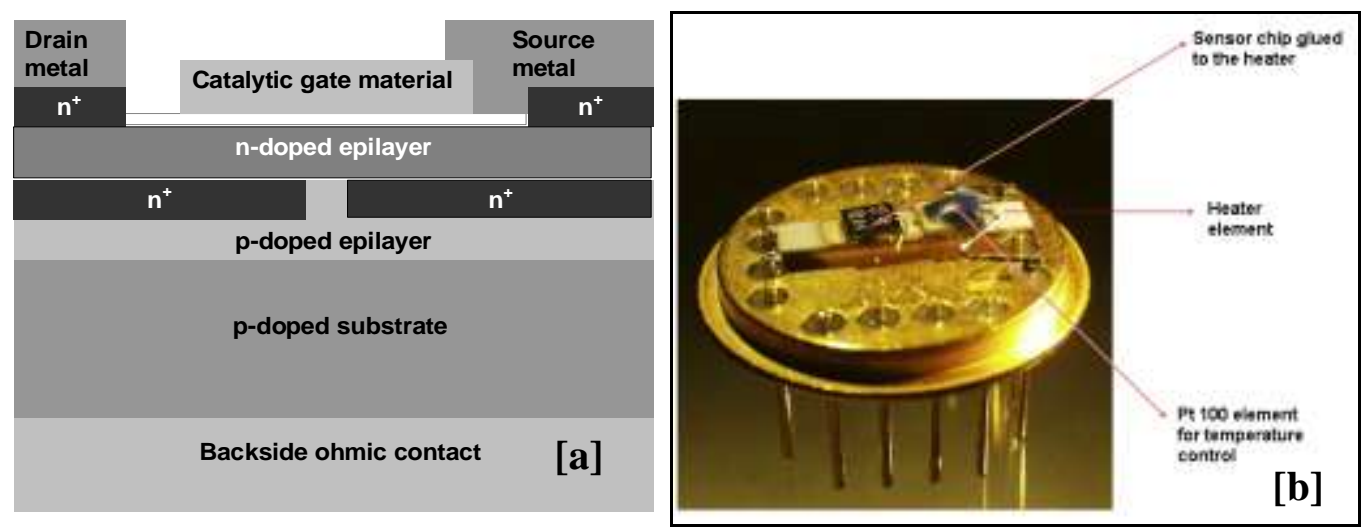

Fig. 1. (a) Schematic diagram of the sensor structure and (b) the mounting of the SiC-FET sensor.

The sensor measurements were performed at a constant source to drain current of 100 $\mu \mathrm{A}$, taking the drain to source/gate voltage as the sensor signal. The sampling rate used for all the measurements was $1 \mathrm{~s}^{-1}$. The gases used were dry and of $99.99 \%$ purity. The sensors were tested for their responses to different concentrations of methanol $(0.3 \%$ to $5 \%$ ) in $10 \% \mathrm{O}_{2}$ mixed with $\mathrm{N}_{2}$ as the carrier gas at different temperatures ranging from $150^{\circ} \mathrm{C}$ to $350^{\circ} \mathrm{C}$ in steps of 50 , in order to evaluate the sensitivity profile vs. temperature. 
The methanol was produced by blowing the carrier gas through liquid methanol (synthetic grade purity) at room temperature in a gas washing bottle, assuming that the carrier gas got saturated by methanol. The $\mathrm{MeOH}$ containing gas was then mixed in various proportions with the main carrier gas flow, and this procedure did not allow concentration lower than $0.3 \%$. The tested concentration range of the methanol is $0.3 \%$ $5 \%$. The carrier gas composition, $10 \% \mathrm{O}_{2}$ in $\mathrm{N}_{2}$, is typical for diesel exhausts and flue gases. It should be noted that according to our experience, there is usually no difference in the sensor response to test gases containing $10 \%$ or $20 \% \mathrm{O}_{2}$ in $\mathrm{N}_{2}$. The exposure to the test gas was performed during 3 min and recovery in carrier gas was allowed for 3 min. The selectivity and cross sensitivity of the sensors were studied for hydrogen and propene.

\section{Results}

We studied the sensing characteristics with different methanol concentrations in 10 or $20 \% \mathrm{O}_{2}$ in $\mathrm{N}_{2}$ as carrier gas. The response is defined as the change in voltage in presence

of methanol to the voltage in air at constant current and is expressed as $\Delta \mathrm{V}=\left(V_{a}-V_{g}\right)$ where $V_{\mathrm{a}}$ is the voltage in air, and $V_{\mathrm{g}}$ is the voltage in presence of methanol gas. The response time of the sensor was calculated as the time to reach the sensor response to $90 \%$ of its saturation value on exposure to sensing gas mixed with 10 or $20 \% \mathrm{O}_{2}$ in $\mathrm{N}_{2}$, and the recovery time was calculated as the time corresponding to the decrease of the sensor response by $90 \%$ of its saturation value in the carrier gas $[15,16]$. 
Methanol response vs. temperature characteristics for both Ir and Pt gate FET sensors were plotted from the repeated cycle transient response at different temperatures and are shown in Fig. 2. The operation temperature corresponding to maximum response was $250^{\circ} \mathrm{C}$ for the $\mathrm{Ir}$ gate sensor and $200^{\circ} \mathrm{C}$ for the Pt gate sensor. The magnitude of the gas response was also found to be quite high for the latter sensor with a maximum of about 2 V. The lower temperature for maximum response as well as the higher value of the response of Pt sensors as compared to Ir sensors was also observed for other gases $\left(\mathrm{H}_{2}\right.$,

$\mathrm{NH}_{3}, \quad \mathrm{CO}, \mathrm{NO} / \mathrm{NO}_{2}$, $\mathrm{C}_{3} \mathrm{H}_{6}$ ) in ref. [9].

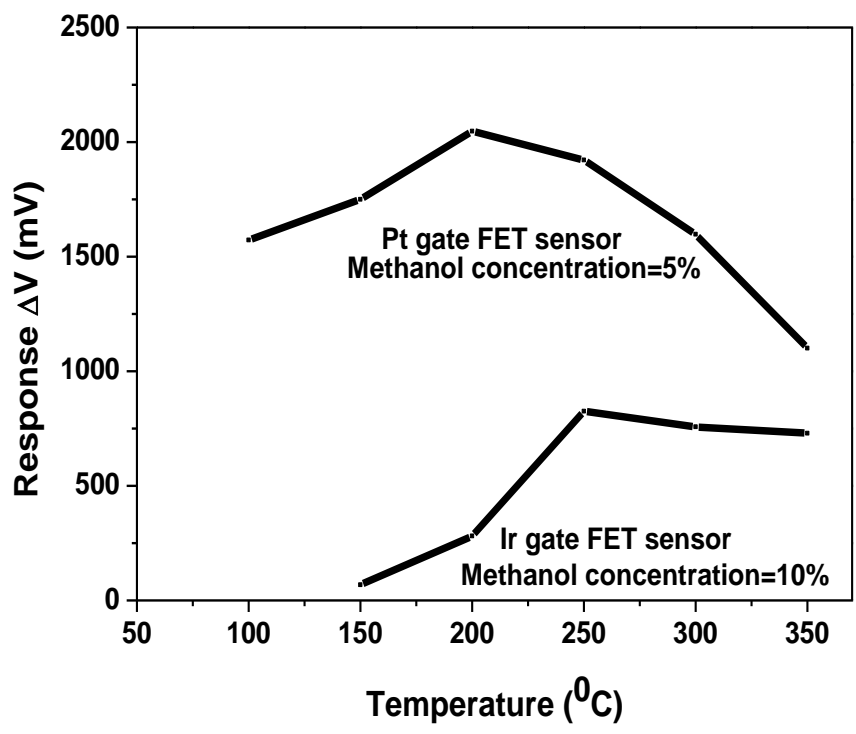

Temperature (으)

Fig. 2. Response vs. temperature characteristics of Ir gate and Pt gate $\mathrm{SiC}$-FET sensors for methanol in $10 \% \mathrm{O}_{2} / \mathrm{N}_{2}$

Fig. 3 displays the transient signals for the sensors at different concentrations of methanol $(0.3 \%, 0.43 \%, 0.57 \%, 0.71 \%, 0.84 \%, 0.98 \%, 1.11 \%, 1.23 \%, 1.36 \%, 1.95 \%, 2.5 \%, 3$, $3.46 \%, 3.88 \%, 4.28 \%, 4.65 \%$ and $5 \%)$ and at the respective maximum operation 
temperature, showing the expected increase in the response with increasing methanol concentrations. Especially for the Pt sensor, the signal to methanol behavior was very stable with minimum drift in the base line, while the Ir sensor needs longer recovery time in order to fully return to the baseline. Figure 2 indicates that for $\mathrm{Ir}$ an operation temperature of $350^{\circ} \mathrm{C}$ would also be possible and would likely increase the speed of response. This will be further investigated in future studies.
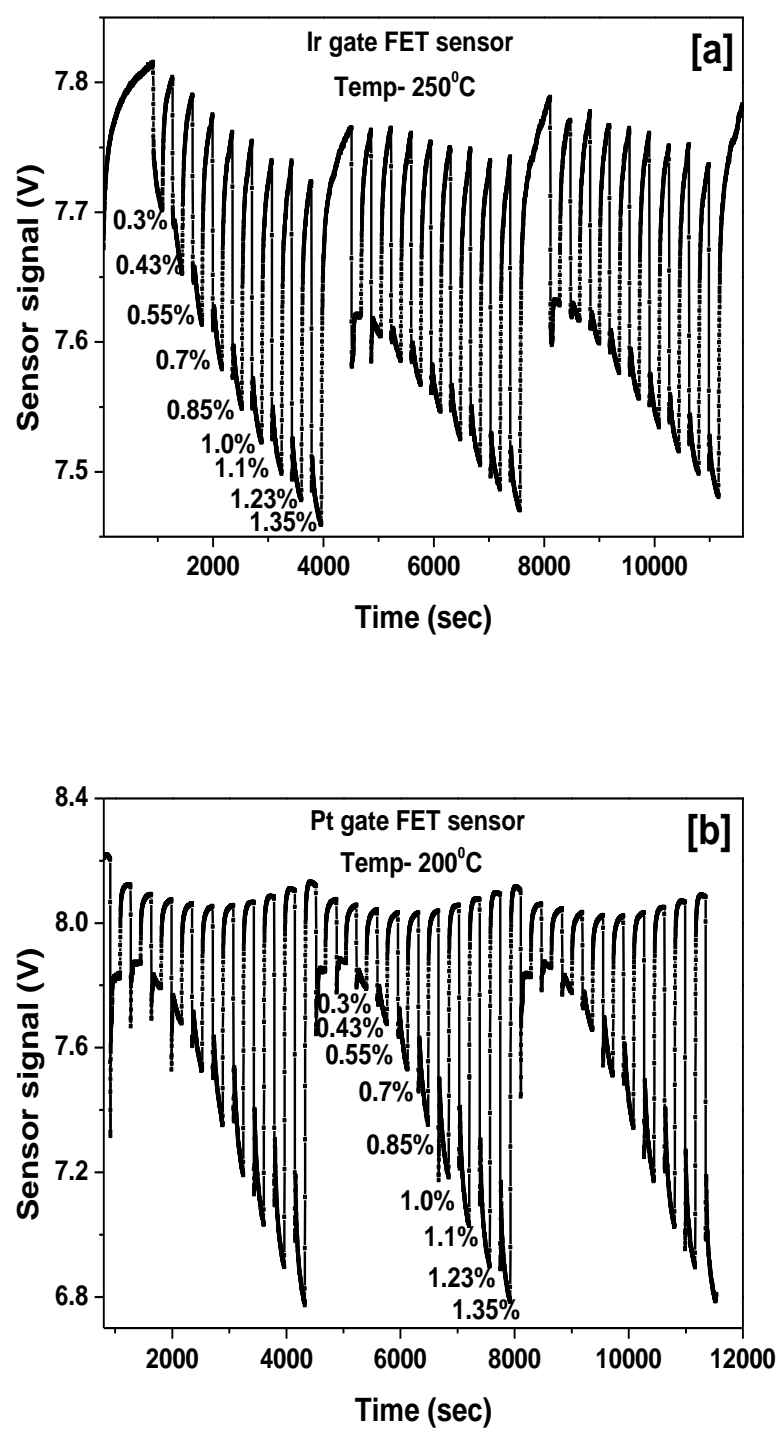
Fig. 3. Transient signal characteristics at different concentration of methanol in $10 \% \mathrm{O}_{2} /$ $\mathrm{N}_{2}$ for (a) Ir gate and (b) Pt gate SiC-FET sensors.

Fig. 4 shows the change in response versus methanol concentration for both samples. For the Ir gate sensor, the response increases almost linearly with increasing concentration, that is Ir shows a large dynamic range of at least $0-5 \%$ for detection of methanol. The Pt gate FET sensor shows an almost linear increase of the response for lower methanol concentrations, and then the slope of the curve decreases and the response reaches saturation at higher concentrations. Neither the Ir nor the Pt sensor response curve could be fitted by the Langmuir isotherm, which indicates that the sensing process probably cannot be reduced to a simple adsorption-desorption phenomenon, as further discussed below.

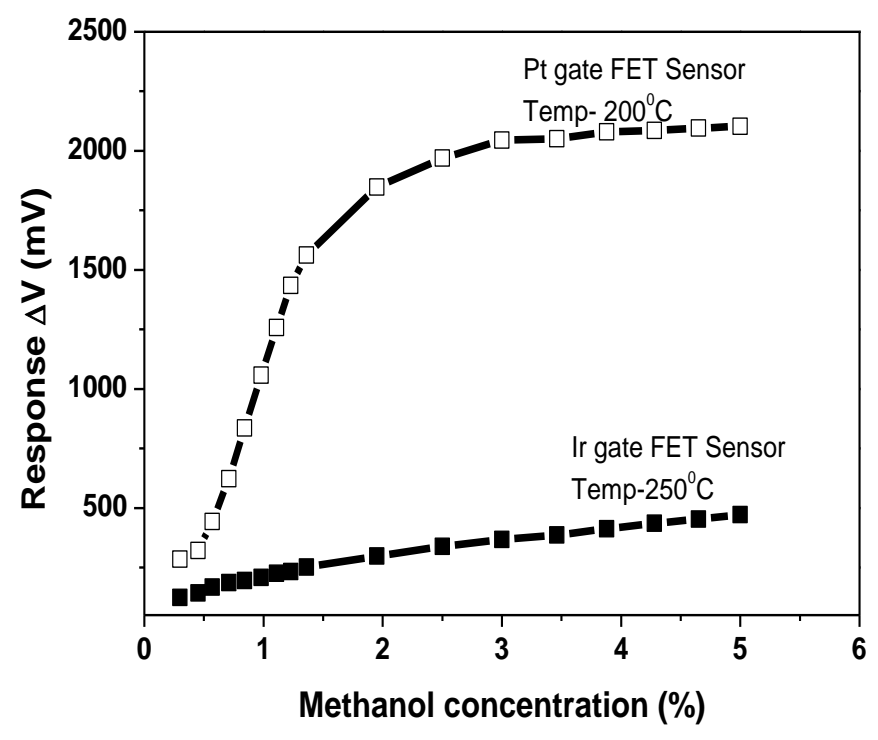

Fig. 4. Response vs. methanol concentration (carrier gas: $10 \% \mathrm{O}_{2} / \mathrm{N}_{2}$ ) characteristics of Ir gate and $\mathrm{Pt}$ gate SiC-FET sensors. 
To investigate the interaction of $\mathrm{MeOH}$ with $\mathrm{Pt}$ and Ir further, quantum-chemical calculations were carried out. The Gaussian03 [17] program was used to perform density functional theory B3LYP/LanL2MB [18-20] computations for metal particles with various degrees of $\mathrm{MeOH}$ coverage, as shown in Fig. 5. A 14-atom Pt or Ir cluster was employed as a compromise between cluster size and computational speed. Methanol was found to adsorb to the surface via its oxygen atom at a distance of about $2 \AA$ for both Pt and Ir. At the Pt cluster, the adsorption energy of a single $\mathrm{MeOH}$ molecule is $235 \mathrm{~kJ} / \mathrm{mol}$. But when the surface of the particle is covered with multiple adsorbates to form approximately half (5 MeOH) and full (14) monolayers the adsorption energy decreased to $193 \mathrm{~kJ}$ per mol MeOH. For the Ir particle the trend is found to be the same, although $\mathrm{MeOH}$ binds somewhat stronger to Ir than to Pt, e.g. $290 \mathrm{~kJ} / \mathrm{mol}$ for a single adsorbate, which decreased to $143 \mathrm{~kJ}$ per mol MeOH (14 monolayers). One of the prerequisites for the Langmuir isotherm to apply is that the adsorption energy per adsorbate should be independent of coverage, which from the calculations is not the case and thus could be the explanation for the observed non-Langmuir behavior of the response curves.

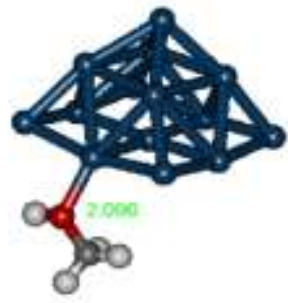

a)

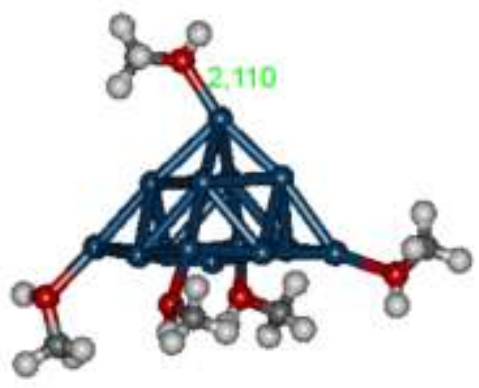

b)

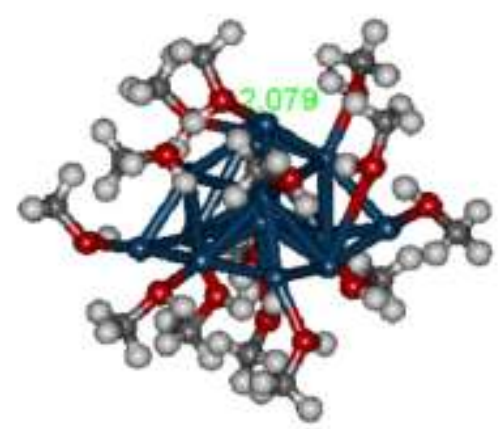

c)

Fig. 5. Platinum clusters with various amount of $\mathrm{MeOH}$ adsorbates from quantumchemical calculations. a) single adsorbate, b) 5 adsorbates and c) 14 adsorbates. 
Table 1 presents the response, the response time and recovery time of both sensors. A minimum in the response time of $2.5 \mathrm{~s}$ and a recovery time of $9 \mathrm{~s}$ was observed for the $\mathrm{Pt}$ gate sensor at $1 \%$ methanol concentration, while the corresponding minima for the Ir sensor were $3 \mathrm{~s}$ and $22 \mathrm{~s}$ for $5 \% \mathrm{MeOH}$. The stability of the sensors was tested through subjecting the sensors to 3 min pulses of $0.3 \%$ methanol in carrier gas with 3 min outgassing repeated with 1 hour in between for a total of 5 hours at their maximum operation temperature, see Figs. 6. It is clear from the figures that, although the response is higher for the Pt gate sensor, in this study the Ir gate sensor shows better stability.

Table 1. Response, response time and recovery time of Ir gate and Pt gate SiC-FET sensors at different methanol concentrations in $10 \% \mathrm{O}_{2} / \mathrm{N}_{2}$ as carrier gas corresponding to their optimum operating temperature

\begin{tabular}{cccccc}
\hline $\begin{array}{c}\text { Type of } \\
\text { sensor }\end{array}$ & $\begin{array}{c}\text { Operating } \\
\text { temperature } \\
(0 \mathrm{C})\end{array}$ & $\begin{array}{c}\text { Methanol } \\
\text { concentration } \\
(\%)\end{array}$ & $\begin{array}{c}\text { Response } \\
\text { voltage } \\
(\mathrm{mV})\end{array}$ & $\begin{array}{c}\text { Response } \\
\text { time } \\
(\mathrm{s})\end{array}$ & $\begin{array}{c}\text { Recovery } \\
\text { time }\end{array}$ \\
\hline $\begin{array}{c}\text { Iridium } \\
\text { gate FET } \\
\text { sensor }\end{array}$ & 250 & 0.3 & 124 & 5 & 64 \\
\hline & & 1 & 208 & 4 & 46 \\
\hline $\begin{array}{c}\text { Ptatinum } \\
\text { gate FET } \\
\text { sensor }\end{array}$ & 200 & 5 & 472 & 3 & 22 \\
\hline & & 1 & 221 & 4 & 37 \\
\hline
\end{tabular}

To study the selectivity of the sensors both were exposed to hydrogen $(0.05 \%, 0.1 \%$, and $0.15 \%)$ and propene $(0.02 \%, 0.03 \%$, and $0.04 \%)$ mixed with the carrier gas of $10 \%$ oxygen in nitrogen. The corresponding transient signal characteristics of both sensors are given in Figs. 7 and 8. The response for different concentrations of hydrogen and propene at maximum operating temperatures for methanol are given in Table 2. For 

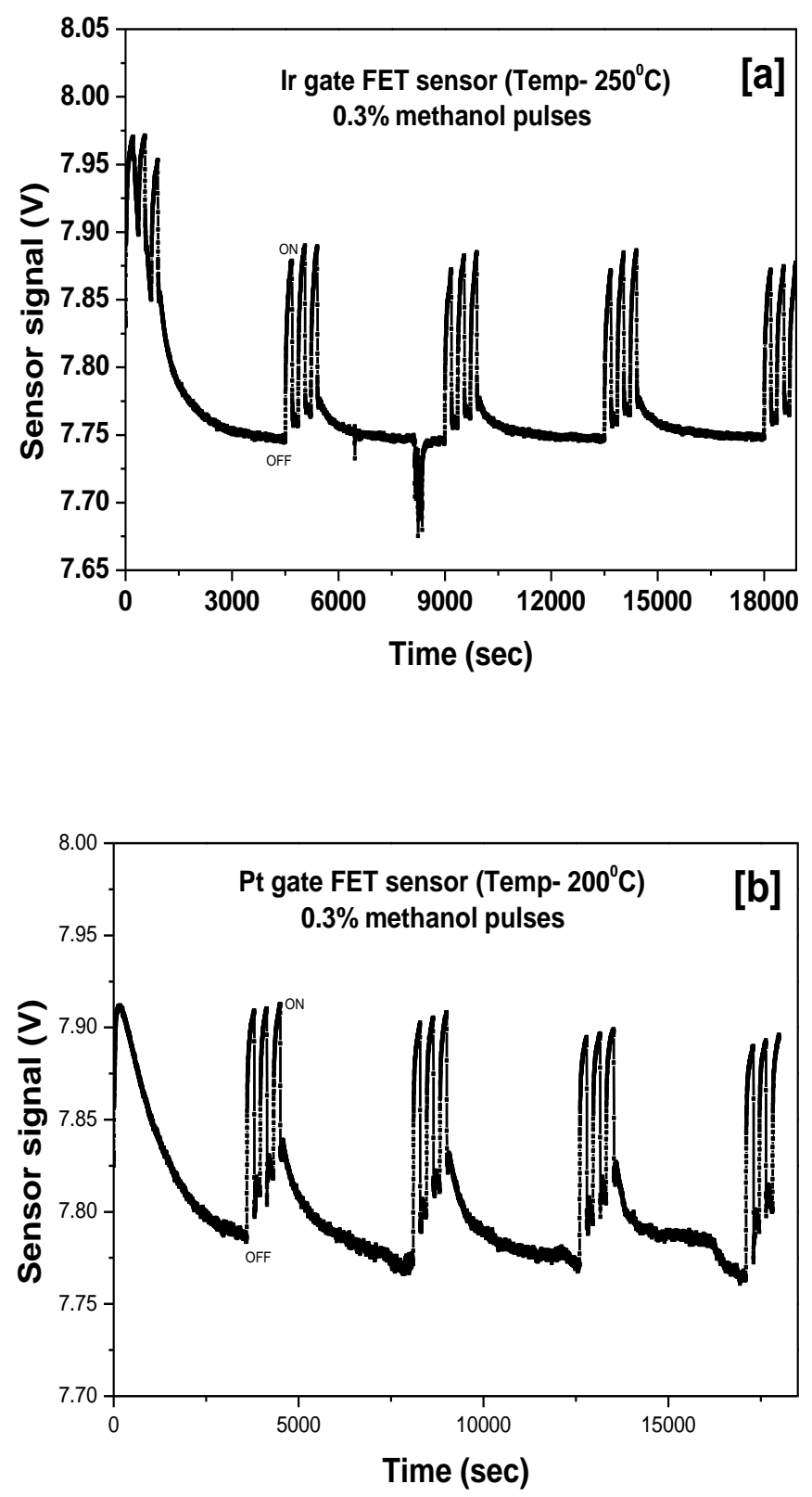

Fig. 6. Stability study of (a) Ir gate and (b) Pt gate SiC-FET sensors with $0.3 \%$ methanol pulses in $10 \% \mathrm{O}_{2}$ in $\mathrm{N}_{2}$ as the carrier gas.

$0.05 \%$ hydrogen concentration the response is shown to be quite high, $220 \mathrm{mV}$ for Ir gate and $845 \mathrm{mV}$ for Pt gate sensor, but for the $0.04 \%$ propene concentration it is only 45 
$\mathrm{mV}$ for $\mathrm{Ir}$ gate and $25 \mathrm{mV}$ for $\mathrm{Pt}$ gate sensor, which corresponds well to earlier measurements, e.g. in Ref. [9]. Therefore it can be concluded that both sensors are highly sensitive for hydrogen but not sensitive for propene at the operation temperatures used in this investigation.

Table 2. Selectivity and cross sensitivity studies. Response of Ir gate and Pt gate SiC-FET sensors at different concentrations of hydrogen, propene and mixtures of these gases with methanol in $10 \% \mathrm{O}_{2} / \mathrm{N}_{2}$ as carrier gas at the chosen operation temperature for methanol detection.

\begin{tabular}{|c|c|c|c|}
\hline Test gas & $\begin{array}{c}\text { Concentration } \\
(\%)\end{array}$ & $\begin{array}{c}\text { Response Ir } 250^{\circ} \mathrm{C} \\
(\mathrm{mV})\end{array}$ & $\begin{array}{c}\text { Response Pt } 200^{\circ} \mathrm{C} \\
(\mathrm{mV})\end{array}$ \\
\hline $\mathrm{H}_{2}$ & 0.05 & 222 & 846 \\
\hline $\mathrm{H}_{2}$ & 0.1 & 517 & 1239 \\
\hline $\mathrm{H}_{2}$ & 0.15 & 913 & 1519 \\
\hline Propene & 0.02 & 39 & 18 \\
\hline Propene & 0.03 & 42 & 23 \\
\hline Propene & 0.04 & 43 & 25 \\
\hline $\begin{array}{l}\text { Methanol (before } \\
\left.\qquad \mathrm{H}_{2}\right)\end{array}$ & 0.3 & 104 & 97 \\
\hline $\begin{array}{c}\text { Methanol }+\mathrm{H}_{2} \\
\text { (Cross sensitivity) }\end{array}$ & $0.3+0.02$ & 187 & 522 \\
\hline $\begin{array}{c}\text { Methanol (before } \\
\text { propene) }\end{array}$ & 0.3 & 103 & 112 \\
\hline $\begin{array}{c}\text { Mehtanol + } \\
\text { propene } \\
\text { (Cross sensitivity) }\end{array}$ & $0.3+0.02$ & 112 & 114 \\
\hline
\end{tabular}

Cross sensitivity studies using hydrogen and propene were also carried out for both Ir and Pt gate sensors. The corresponding transient signal characteristics are shown 

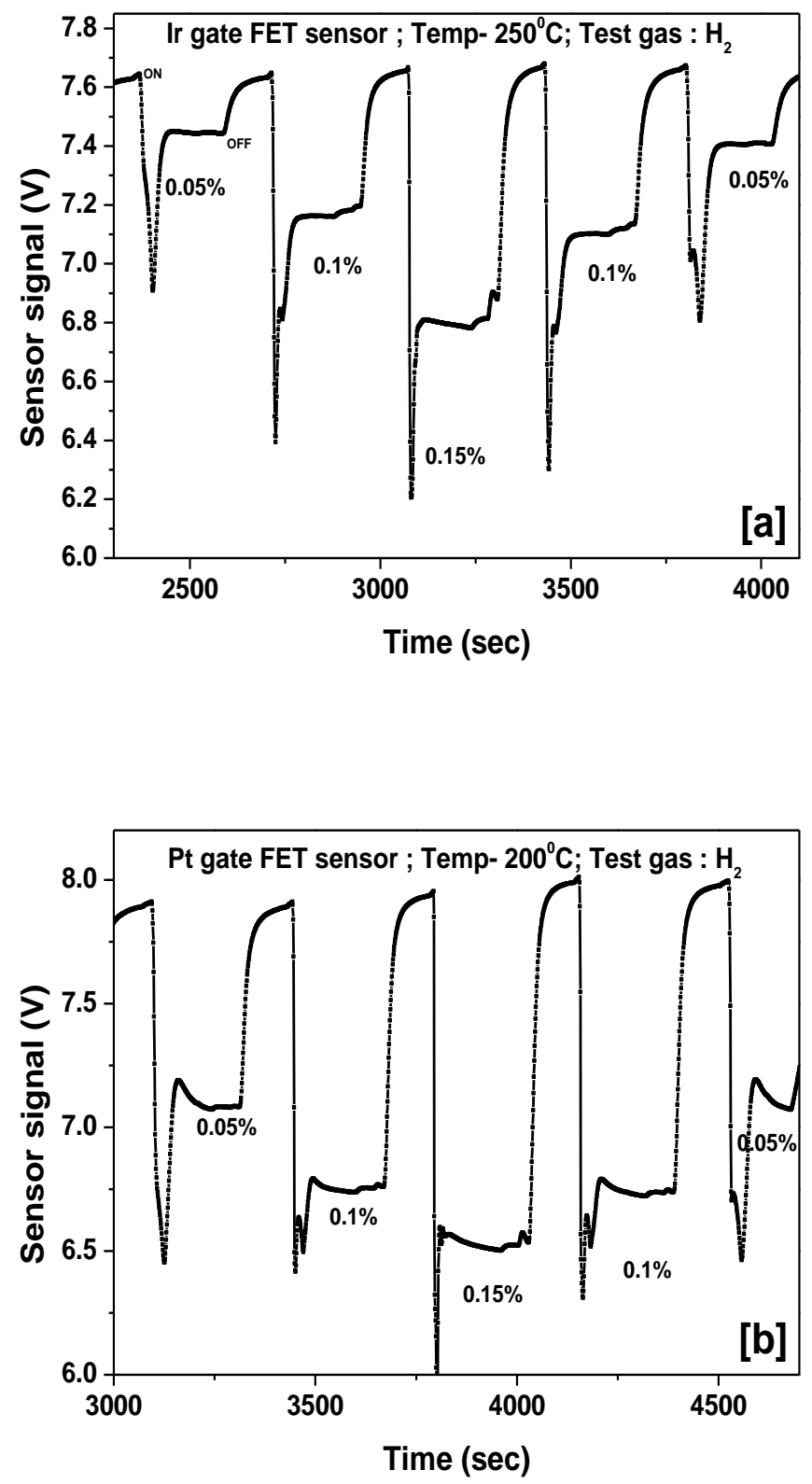

Fig. 7. The response of (a) Ir gate and (b) Pt gate SiC-FET sensors to hydrogen. 

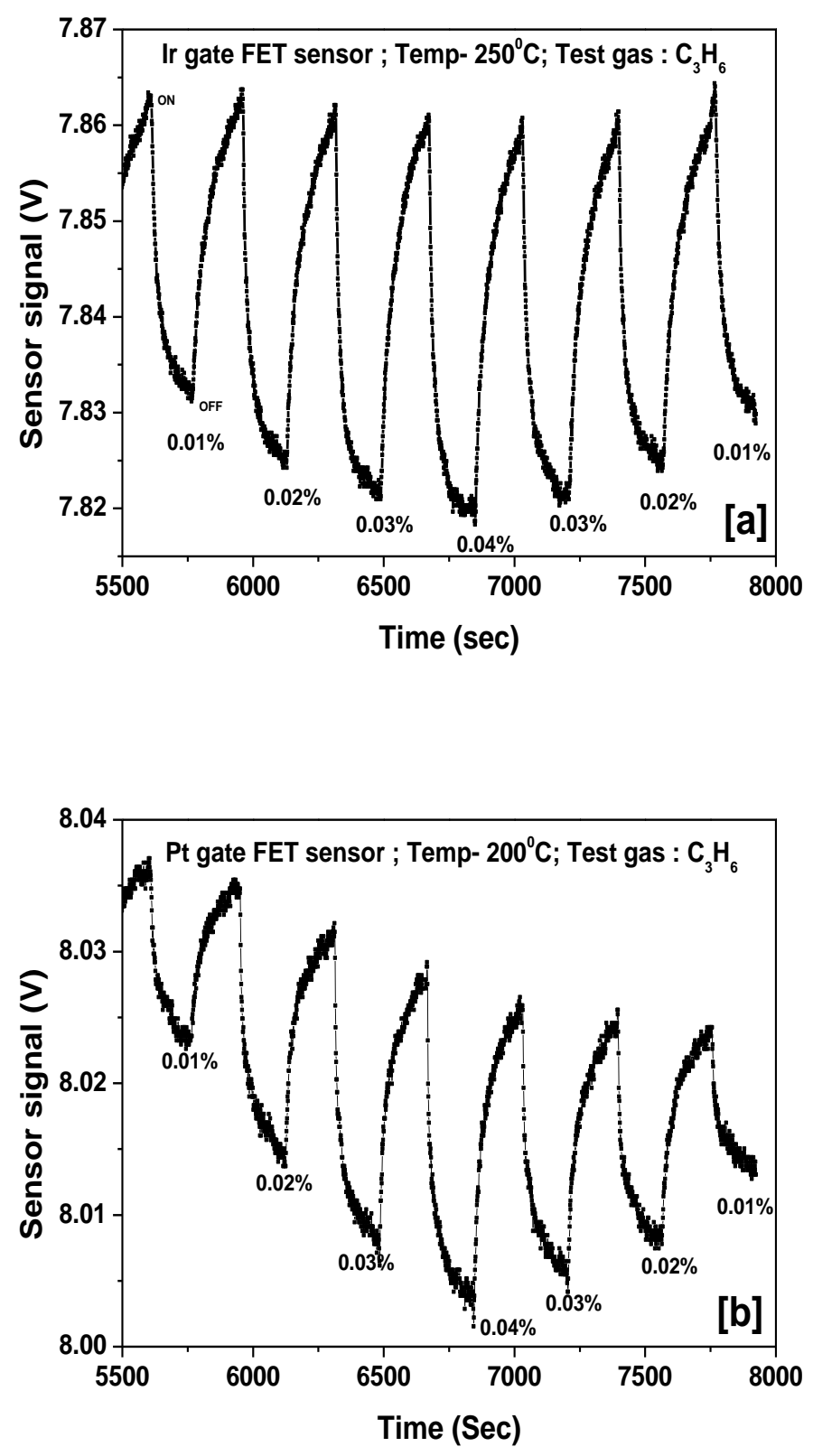

Fig. 8. Response of (a) Ir gate and (b) Pt gate SiC-FET sensors to propene.

in Figs. 9 and 10. Here the first three pulses are for $0.3 \%$ methanol only and the following pulses are for $0.3 \%$ methanol mixed with $0.02 \%$ hydrogen and $0.02 \%$ propene respectively, with $10 \% \mathrm{O}_{2}$ mixed with $\mathrm{N}_{2}$ as carrier gas in all cases. Table 2 also presents 

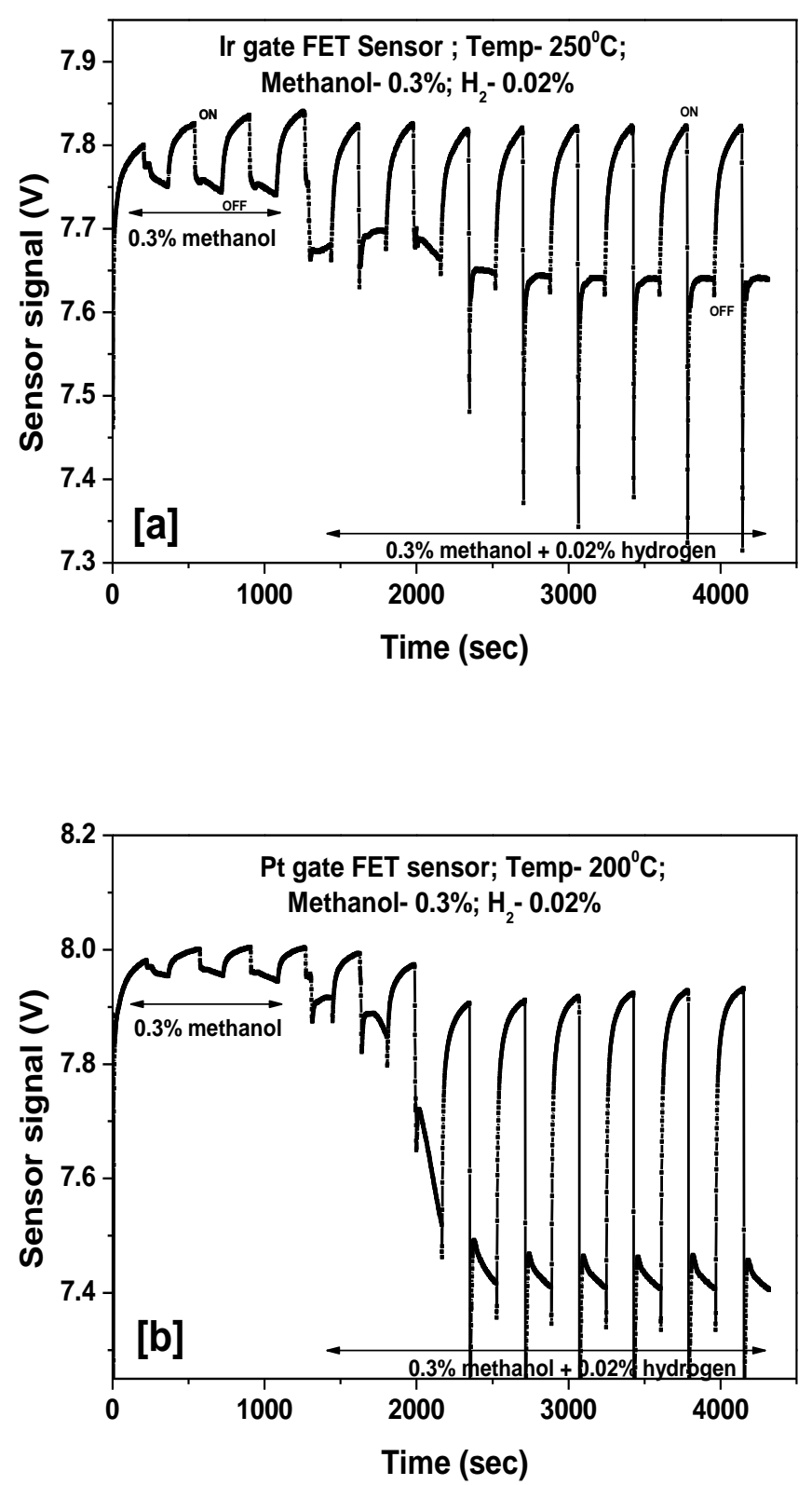

Fig. 9. Cross sensitivity study of (a) Ir gate and (b) Pt gate SiC-FET sensors between methanol and hydrogen. 

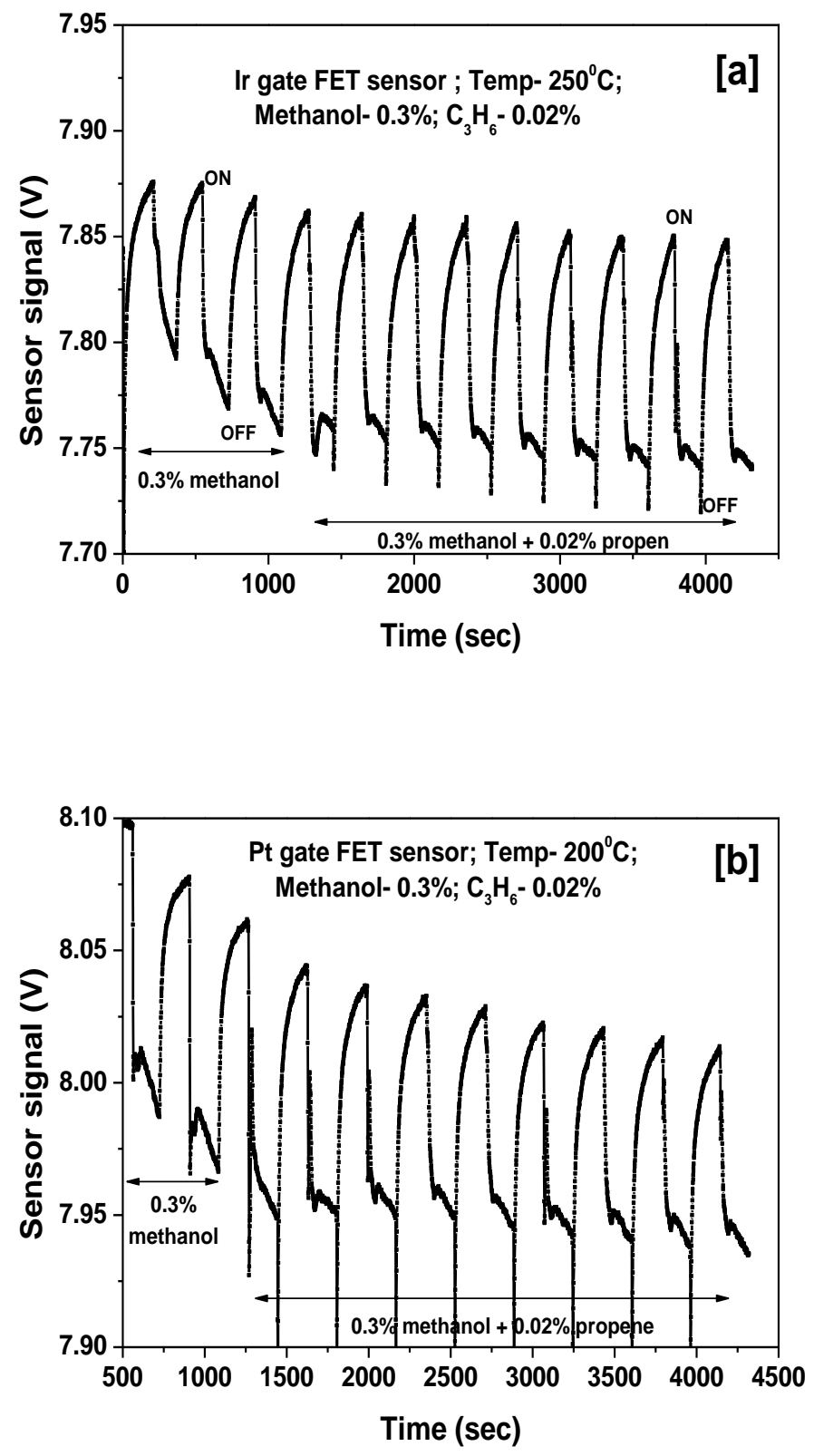

Fig. 10. Cross sensitivity study of (a) Ir gate and (b) Pt gate SiC-FET sensors between methanol and propene.

the response to methanol with hydrogen or propene present in the gas mixture. The response increases from 105 to $185 \mathrm{mV}$ for the Ir gate sensor, and from 95 to $520 \mathrm{mV}$ for the Pt gate sensor when hydrogen was mixed with methanol. However, the response 
increases from 105 to $110 \mathrm{mV}$ for the Ir gate sensor, and from 110 to $115 \mathrm{mV}$ for Pt gate sensor when propene was mixed with methanol. Thus both sensors show large cross sensitivity for hydrogen but not for propene at the chosen operation temperatures for the methanol detection.

\section{Discussion and Future work}

As stated in the introduction, the large number of applications of methanol, e.g. as a liquid fuel produced from the conversion of $\mathrm{CO}_{2}$, as well as its toxicity justifies the development of a methanol sensor. The work performed in this study show an interesting complex behavior for methanol detection by SiC-FET sensors, which is different for Pt and Ir gates.

The investigation of the methanol sensitivity of Pt and Ir gate SiC-FET devices was obvious as a starting point since these sensors are the most characterized for this type of gas sensors $[9,21]$. The high concentration of the tested methanol originates from practical circumstances, since for this introductory study we choose to produce methanol molecules from the well-known method of blowing air through methanol in a gas washing bottle. On the other hand, the high concentration also introduced the interesting extremely high response of the Pt gate sensor, for which we can only speculate about the reason. It can be assumed that part of the response is due to hydrogen atoms decomposed from methanol, which are detected as $\mathrm{OH}$ groups formed on the insulator surface in the normal way for hydrogen containing gases by these sensors [22]. A theoretical value for the saturated hydrogen response for a thick film sensor is about $800 \mathrm{mV}$ and for a porous 
film about $200 \mathrm{mV}$ adds to the response from consumption of oxygen ions adsorbed on the insulator surface by the hydrogen $[23,24]$. The transistor devices used as sensors provide some amplification through the transistor gain (transconductance), still a response of $2 \mathrm{~V}$ has to include also detection of more species. This could be decomposition products of methanol adsorbed on top of $\mathrm{OH}$ groups or at other sites on the insulator surface and / or at the metal - insulator border. It should be pointed out that field effect sensors do not detect resistivity change in the catalytic gate material like in Refs. [4-7], but charging effects of the gate area. The size of the response and the recovery time for, e.g., $1 \%$ methanol revealed in Table 1 is another indication that different detection mechanisms are involved in the case of Pt and Ir at the rather high concentrations of methanol investigated here.

The difference in stability of the response of Pt and Ir gate sensors is mainly due to the tendency of the gate material to restructure during the high temperature operation. This depends on several parameters like grain size and substrate but also on the melting point of the metal, which for Ir is considerably higher $\left(2410^{\circ} \mathrm{C}\right)$ as compared to $\mathrm{Pt}\left(1772^{\circ} \mathrm{C}\right)$ [25]. The better stability of Ir is reflected in the stability tests in Fig. 5. This makes it even more interesting to investigate Ir also at higher operation temperature in future work.

More work should be performed e.g by DRIFT (Diffuse Reflectance IR Fourier Transform) spectroscopy [23] to reveal the details in the detection mechanism in these measurements. For example, the extremely high response to high concentrations of 
methanol for the Pt gate SiC-FET sensor will be interesting to study. More quantumchemical calculations on the reaction mechanisms will also be carried out. In particular more detailed studies are necessary to better understand the difference in response behavior between Pt and Ir as a consequence of their different electronic structure (both Pt and Ir are cubic close packed metals). The interplay between methanol, hydrogen and oxygen on Pt and Ir surfaces is especially interesting to study in relation to the results in Table 2. Further studies are planned to investigate the methanol response over a larger concentration range starting at around $10 \mathrm{ppm}$. The response to Ir at temperatures above $300^{\circ} \mathrm{C}$ may give interesting results and will be investigated. There are other sensing materials with potential for selective methanol sensing and interesting to include in a sensor array, which might be needed in order to reach a viable methanol sensor system.

\section{Conclusions}

Methanol is an interesting alternative vehicle fuel, either in itself in an internal combustion engine or as a hydrogen source for fuel cells The possibility to synthesize methanol from carbon dioxide has increased the interest even more, and justifies sensor development. Silicon carbide based FET sensors were tested regarding their response to methanol at elevated temperature. Two catalytic gate metals, Ir and Pt, were tested so far. The Pt gate FET sensor (operation temperature $200^{\circ} \mathrm{C}$ ) showed higher sensitivity to methanol compared to the Ir gate sensor (operation temperature chosen to $250^{\circ} \mathrm{C}$ ) but the stability of the sensor was found to be better for the latter one. The response curves were non-Langmuir in nature, which could be due to the adsorption energies being dependent upon the degree of coverage as supported by quantum-chemical calculations. Both 
sensors showed a low response to propene, while the response to hydrogen is even higher as compared to methanol and also with clear cross sensitivity at the chosen operation temperatures for methanol detection. More sensing materials are interesting for future studies and the detection mechanism needs further clarification. For example, a very high response of the $\mathrm{Pt}$ gate sensor implies that not only dissociated hydrogen atoms are involved in the detection of methanol.

\section{Acknowledgements}

Dr. Jayita Kanungo thankfully acknowledges The Swedish Research Council, VR 3482007-6837, for providing the financial assistance during her visit to the sensor research group at Linköping University, Sweden, where the work was carried out. The Swedish

Research council is also acknowledged for support through the grant VR 621-2008-3229 and a faculty support is acknowledged from Linköping University.

\section{References:}

[1] G.A. Olah, After Oil and Gas: Methanol Economy, Catal. Lett. 93 (2004) 1-2.

[2] R. Raudaskoski, E. Turpeinen, R. Lenkkeri, E. Pongracz, R.L. Keiski, Catalytic activation of $\mathrm{CO} 2$ : Use of secondary $\mathrm{CO} 2$ for the production of synthesis gas and for methanol synthesis over zirconia containing catalysts, Catal. Today 144 (2009) 318-323.

[3] X. Guo, D. Mao, G. Lu, S. Wang, G. Wu, Glycine-nitrate combustion synthesis of $\mathrm{CuO}-\mathrm{ZnO}-\mathrm{ZrO}_{2}$ catalysts for methanol synthesis from $\mathrm{CO}_{2}$ hydrogenation, Journal of Catalysis 271 (2010) 178-185. 
[4] N.G. Patel, P.D. Patel, V.S. Vaishnav, Indium tin oxide (ITO) thin film gas sensor for detection of methanol at room temperature, Sensors and Actuators B 96 (2003) $180-189$.

[5] X.L. Cheng, H. Zhao, L.H. Huo, S. Gao, J.G. Zhao, ZnO nanoparticulate thin film: preparation, characterization and gas-sensing property, Sens. Actuators B 102 (2004) 248-252.

[6] K. Arshak, I. Gaiden, Development of a novel gas sensor based on oxide thick films, Mater. Sci. Eng. B 118 (2005) 44-49.

[7] G. Neri, A. Bonavita, G. Rizzo, S. Galvagno, S. Capone, P. Siciliano, Methanol gas-sensing properties of $\mathrm{CeO} 2-\mathrm{Fe} 2 \mathrm{O} 3$ thin films, Sens. Actuators B 114 (2006) $687-695$.

[8] SenSiC AB, Isafjordsgatan 39B, SE-164 40 Kista, Sweden.

[9] M. Andersson, P. Ljung, M. Mattsson, M. Lofdahl and A. Lloyd Spetz, Investigations on the possibilities of a MISiCFET sensor system for OBD and combustion control utilizing different catalytic gate materials, Topics in Catalysis 30/31 (2004) 365-368.

[10] H. Amandusson, L.-G. Ekedahl, H. Dannetun, Methanol-induced hydrogen permeation through a palladium membrane, Surface Science 442 (1999) 199-205

[11] S. C. Barton, B. L. Murach, T. F. Fuller, and A. C. West, A methanol sensor for portable direct methanol fuel cells, J. Electrochem. Soc., 145 (1998) 3783-3788.

[12] S. R. Narayanan, T. I. Valdez, and W. Chun, Design and operation of an electrochemical methanol concentration sensor for direct methanol fuel cell systems, Electrochem. Solid-State Lett., 3 (2000) 117-120. 
[13] P.P. Sahay, R.K. Nath, Al-doped ZnO thin films as methanol sensors, Sensors and Actuators B 134 (2008) 654-659.

[14] Acreo AB, Electrum 236, SE-164 40 KISTA, Sweden.

[15] J. Kanungo, H. Saha and S. Basu. Effect of porosity on the performance of surface modified porous silicon hydrogen sensors. Sensors and Actuators B: Chemical, 147 (2010) 145-151.

[16] J. Kanungo, H. Saha and S. Basu. Pd sensitized porous silicon hydrogen sensor influence of $\mathrm{ZnO}$ thin film. Sensors and Actuators B: Chemical, 147 (2010) 128136.

[17] Gaussian 03, Revision C.02, M. J. Frisch, G. W. Trucks, H. B. Schlegel, G. E. Scuseria, M. A. Robb, J. R. Cheeseman, J. A. Montgomery, Jr., T. Vreven, K. N. Kudin, J. C. Burant, J. M. Millam, S. S. Iyengar, J. Tomasi, V. Barone, B. Mennucci, M. Cossi, G. Scalmani, N. Rega, G. A. Petersson, H. Nakatsuji, M. Hada, M. Ehara, K. Toyota, R. Fukuda, J. Hasegawa, M. Ishida, T. Nakajima, Y. Honda, O. Kitao, H. Nakai, M. Klene, X. Li, J. E. Knox, H. P. Hratchian, J. B. Cross, V. Bakken, C. Adamo, J. Jaramillo, R. Gomperts, R. E. Stratmann, O. Yazyev, A. J. Austin, R. Cammi, C. Pomelli, J. W. Ochterski, P. Y. Ayala, K. Morokuma, G. A. Voth, P. Salvador, J. J. Dannenberg, V. G. Zakrzewski, S. Dapprich, A. D. Daniels, M. C. Strain, O. Farkas, D. K. Malick, A. D. Rabuck, K. Raghavachari, J. B. Foresman, J. V. Ortiz, Q. Cui, A. G. Baboul, S. Clifford, J. Cioslowski, B. B. Stefanov, G. Liu, A. Liashenko, P. Piskorz, I. Komaromi, R. L. Martin, D. J. Fox, T. Keith, M. A. Al-Laham, C. Y. Peng, A. Nanayakkara, M. 
Challacombe, P. M. W. Gill, B. Johnson, W. Chen, M. W. Wong, C. Gonzalez, and J. A. Pople, Gaussian, Inc., Wallingford CT, 2004.

[18] A. D. Becke, Density-functional exchange-energy approximation with correct asymptotic-behavior, Phys. Rev. A, 38 (1988) 3098-3100.

[19] C. Lee, W. Yang, and R. G. Parr, Development of the Colle-Salvetti correlationenergy formula into a functional of the electron density, Phys. Rev. B, 37 (1988) 785-89.

[20] P. J. Hay and W. R. Wadt, Ab initio effective core potentials for molecular calculations - potentials for the transition-metal atoms Sc to Hg, J. Chem. Phys., 82 (1985) 270-83.

[21] I. Lundström, H. Sundgren, F. Winquist, M. Eriksson, C. Krantz-Rülcker, A. Lloyd Spetz, Twenty-five years of field effect gas sensor research in Linköping, Sensors and Actuators B, 121 (2007) 247-262.

[22] M. Wallin, H. Grönbeck, A. Lloyd Spetz, M. Eriksson, M. Skoglundh, Vibrational analysis of $\mathrm{H}_{2}$ and $\mathrm{D}_{2}$ adsorption on $\mathrm{Pt} / \mathrm{SiO}_{2}$, J. Phys. Chem. B, 109 (2005) 95819588.

[23] E. Becker, M. Andersson, M. Eriksson, A. Lloyd Spetz, M. Skoglundh, Study of the sensing mechanism towards carbon monoxide of platinum based field effect sensors, IEEE Sensors Journal, 11,7 (2011) 1527-1534.

[24] A. Lloyd Spetz, M. Skoglundh and Lars Ojamäe, FET gas sensing mechanism, experimental and theoretical studies, in Solid State Gas Sensing, editors Elisabetta Comini, Guido Faglia, Giorgio Sberveglieri, chapter 4, pp. 153-179, Springer, Norwell MA, USA, ISBN: 978-0-387-09664-3. 
[25] CRC Handbook if Chemistry and Physics, $61^{\text {st }}$ Edition, 1980-1981, CRC Press Inc, Boca Raton Florida 33431, USA.

\section{Table captions:}

Table 1. Response, response time and recovery time of Ir gate and Pt gate SiC-FET sensors at different methanol concentrations in $10 \% \mathrm{O}_{2} / \mathrm{N}_{2}$ as carrier gas corresponding to the chosen operating temperatures.

Table 2. Selectivity and cross sensitivity studies. Response of Ir gate and Pt gate SiC-FET sensors at different concentrations of hydrogen, propene and mixtures of these gases with methanol in $10 \% \mathrm{O}_{2} / \mathrm{N}_{2}$ as carrier gas at the chosen operation temperature for methanol detection.

\section{Figure captions:}

Fig. 1. (a) Schematic diagram of the sensor structure and (b) the mounting of the SiCFET sensor.

Fig. 2. Response vs. temperature characteristics of Ir gate and Pt gate SiC-FET sensors for methanol in $10 \% \mathrm{O}_{2} / \mathrm{N}_{2}$. 
Fig. 3. Transient signal characteristics at different concentration of methanol in $10 \% \mathrm{O}_{2} /$ $\mathrm{N}_{2}$ for (a) Ir gate and (b) Pt gate SiC-FET sensors.

Fig. 4. Response vs. methanol concentration (carrier gas: $10 \% \mathrm{O}_{2} / \mathrm{N}_{2}$ ) characteristics of Ir gate and Pt gate SiC-FET sensors.

Fig. 5. Platinum clusters with various amount of $\mathrm{MeOH}$ adsorbates from quantumchemical calculations. a) single adsorbate, b) 5 adsorbates and c) 14 adsorbates.

Fig. 6. Stability study of (a) Ir gate and (b) Pt gate SiC-FET sensors with $0.3 \%$ methanol pulses in $10 \% \mathrm{O}_{2}$ in $\mathrm{N}_{2}$ as the carrier gas.

Fig. 7. Response of (a) Ir gate and (b) Pt gate SiC-FET sensors to hydrogen.

Fig. 8. Response of (a) Ir gate and (b) Pt gate SiC-FET sensors to propene.

Fig. 9. Cross sensitivity study of (a) Ir gate and (b) Pt gate SiC-FET sensors between methanol and hydrogen.

Fig. 10. Cross sensitivity study of (a) Ir gate and (b) Pt gate SiC-FET sensors between methanol and propene. 


\section{Author Biographies}

Jayita Kanungo received her Ph.D degree in Engineering from Jadavpur University, India, 2010. Now she is working as a research associate at IC Design and Fabrication Centre, Department of Electronics and Telecommunication Engineering, Jadavpur University, Kolkata, India. Her main research interest is development and applications of gas sensor materials and devices.

Mike Andersson received his Ph.D. in applied physics at Linköping University 2007 and completed a Post Doc in sensor science in 2009. He is currently working as a research scientist within the sensor science group at Linköping University as well as within $\mathrm{SenSiC} \mathrm{AB}$. His main research interests concern chemical sensors for high temperature and environmental applications.

Zhafira Darmastuti, PhD student at Applied Physics, Linköping University. She has academic and industrial background in Energy and Environment Engineering. Her main interest is chemical gas sensors for flue gas cleaning in power generation application.

Dr. Sukumar Basu is a retired professor of IIT Kharagpur, India and now he is associated with Jadavpur University, Kolkata, India as Research Advisor. His main topics of research are electronic materials and solid-state gas sensors. At present he is working on synthesis and characterizations of graphene and its oxide derivative for applications as hydrogen \& hydrocarbon sensors. Prof. Basu has published about 200 papers in the peer reviewed national \& international journals and proceedings of the international conferences. He has four book chapters and three Indian patents to his credit. 
Per-Olov Käll, Professor in inorganic chemistry at Linköping University, Sweden. Käll, who received his $\mathrm{PhD}$ in inorganic chemistry at Stockholm University in 1991, has a main interest in materials chemistry. While in the beginning of his academic career Käll studied the synthesis and phase composition of structural ceramics, e.g. silicon nitride based ceramics, in recent years he has been working with synthesis and characterization of nano-sized metal oxide particles and thin films for applications in, e.g., sensors, magnetic resonance imaging, and optical devices. Käll is also interested in the energy issue and believes it is important to develop effective catalysts for the hydrogenation of $\mathrm{CO}_{2}$ to $\mathrm{MeOH}$ and other energy rich hydrocarbons. He has published more than 40 articles in international peer-reviewed scientific journals and about 20 peer-reviewed conference proceedings. He is a member of the board of The Centre in Nano science and technology (CeNano) at Linköping University and of the editorial board of the newly launched journals Open Journal of Inorganic Chemistry and ISRN Nanotechnology.

Lars Ojamäe, Professor in Physical Chemistry at Linköping University since 2008. He received his $\mathrm{PhD}$ in inorganic chemistry at Uppsala University in 1993, worked as postdoc at the Ohio State University and at the University of Turin, as assistant professor at Stockholm University and associate professor and then full professor at Linköping University. He heads the physical chemistry subdivision. His research activities focus on computational-chemistry modeling of chemical reactions at surfaces, solar cells, hydrogen bonding and nanoparticles. 
Anita Lloyd Spetz, Professor in Sensor Science, Chemical Sensors at Linköping University, 2011-2014 50\% FiDiPro professor, Oulu University, Finland. 1995-2006 she was at S-SENCE, Swedish Sensor Centre (centre of excellence). From 2007 she is the Vice Director of the VINN Excellence centre, FunMat, Functional nanostructured Materials. Her research involves SiC-FET high temperature gas sensors with MAX material ohmic contacts, wide band gap material transducers for biosensors, resonator sensors, soot sensors and graphene sensors. She runs application projects with industry, and she is member of the board of SenSiC AB for commercialization of SiC-FET sensors. She has published 160 papers in scientific journals and referenced conference proceedings, 10 book chapters, and has 4 patents. 